\title{
Acute Viral Hepatitis A with Cholestatic Hepatitis Treated with Traditional Korean Medicine : A Case Report
}

\author{
Jun-Young Kim, Jin-Yong Joung, Ji-Young Kang, Chang-Gue Son, Jung-Hyo Cho \\ Dept. of Internal Medicine, College of Korean Medicine, Daejeon University
}

\begin{abstract}
More and more patients suffering from hepatitis A, the number of patients representing symptoms that are uncharacteristic to hepatitis $\mathrm{A}$ is also increasing. There are occasions of serious complications among adult hepatitis A patients that can cause fulminant hepatitis or cirrhosis which can be fatal. A 43-year-old male was diagnosed as acute hepatitis $A$ and was treated at a Western hospital over the course of three months, which included two months of hospitalization. However, his symptoms did not improve, so he was admitted to Oriental hospital. We prescribed Chunggan extract (CGX) four times a day. Acupuncture was performed twice a day. From the twenty-fourth day of admission, the total bilirubin fell under $10 \mathrm{mg} / \mathrm{dL}$ for the first time and next day he was discharged. Following his discharge, he consistently took CGX three times a day. 21 days after discharge all of his symptoms disappeared. This study demonstrated that traditional Korean medicine (TKM) for acute viral hepatitis with cholestatic hepatitis might be effective and safe with no adverse effects.
\end{abstract}

$\overline{\text { Key Words }}$ : Acute viral hepatitis A, Cholestatic hepatitis, Traditional Korean medicine

\section{Introduction}

Hepatitis A virus (HAV) is a virus which infects more than 1.5 million people worldwide per year and is usually spread through contaminated food and water $^{1)}$. Most children infected HAV under six years of age are asymptomatic and they have lifelong immunity $^{2}$. However, patients over six years of age often have symptoms such as jaundice, nausea, vomiting, poor appetite, fever, fatigue, abdominal pain, etc. With most patients usually fully recovering from HAV infection naturally within 2 months, it has not been a cause for major concern of public health ${ }^{3}$.

However, with the improving sanitation levels in Korea thanks to socio-economic development, chances for asymptomatic infection in early childhood have decreased, and this has led to a sharp decrease in seroprevalence of antibody for HAV in young people ${ }^{4)}$.

With more and more patients suffering from hepatitis $\mathrm{A}$, the number of patients representing symptoms that are uncharacteristic to hepatitis $\mathrm{A}$ is also on the increase. Most hepatitis A patients tend to recover from the illness natural without any complications; however, there are occasions of serious complications among adult hepatitis A patients such as acute renal failure, cholestatic hepatitis, relapsing hepatitis, and prolonged course. Complications such as these can cause fulminant hepatitis or cirrhosis, which can be fatal ${ }^{5}$. Cholestatic

\footnotetext{
- Received : 31 October 2015

- Revised : 21 December 2015

- Accepted : 21 December 2015

- Correspondence to: Jung-Hyo, Cho

Dept. of Internal Medicine, Daejeon Oriental Hospital of Daejeon University

34929, 176-9 Daeheung-ro, Jung-gu, Daejeon, South Korea

Tel : +82-42-229-6806, Fax : +82-42-254-3403, E-mail : choajoa@dju.kr
} 
hepatitis accounts for between $0.8-5.2 \%$ of hepatitis A cases ${ }^{5-10)}$. Together with increasingly more cases of hepatitis A being reported, the number of patients who have cholestatic hepatitis arising from hepatitis A also has increased.

Hepatitis A is currently being treated by sufficient nutrition, vitamin supply and sufficient rest. There are also no special treatments for cholestatic hepatitis, with conservative treatment being used. Ursodeoxycholic acid (UDCA) and adrenocortical hormone are used to treat skin itching caused by cholestatic hepatitis; however there are occasions where symptoms are so severe as to call for liver transplantation. But with dissatisfaction regarding efficacy and many cases of adverse effects being report, the need for a new treatment is growing ${ }^{11)}$.

To date there have been five studies done on hepatitis A treated with traditional Korean medicine (TKM) in Korea ${ }^{12-16)}$. Among these there have been no studies done on hepatitis A with complications such as cholestatic hepatitis, and all studies were done on short-term lapses. This study reports on cases where TKM has caused improvements in patients diagnosed with cholestatic hepatitis arising from acute hepatitis A with a lapse exceeding four months who have been hospitalized and received conservative treatment in a Western hospital. The study aims to bring attention to hepatitis $\mathrm{A}$ in the field of TKM, and also to demonstrate the possibility of TKM playing a significant role in the treatment of hepatitis A.

\section{Case Report}

\section{Background of patients and diagnosis}

On $10^{\text {th }}$ May, 2015, a 43-year-old male patient visited showing signs of jaundice and complaining of severe fatigue, skin itching, fever, poor appetite, and dark-colored urine and grey-colored stools. He was diagnosed as having acute Hepatitis A and was treated at a Western hospital over the course of about three months, which included two occurrences of hospitalization; once from $29^{\text {th }}$ May $-26^{\text {th }}$ June 2015 , and again from $17^{\text {th }}$ July $-22^{\text {nd }}$ August 2015. However, his symptoms did not improve, so he was admitted to a TKM clinic on $25^{\text {th }}$ August. At the time of admission, the patient's skin was dark yellow all over, and his sclera was found to be dark yellow also (Table 1). He showed symptoms such as all-over pruritus and fatigue, his urine was still dark in color and his stools grey. He did not suffer from fever and abdominal pain in the right side around the liver. Before jaundice first appeared, he did not consume any suspicious foods or travel abroad, and has no

Table 1. The Changes of Symptom, Color of Urine, Stool and Sclera During Hospitalization.

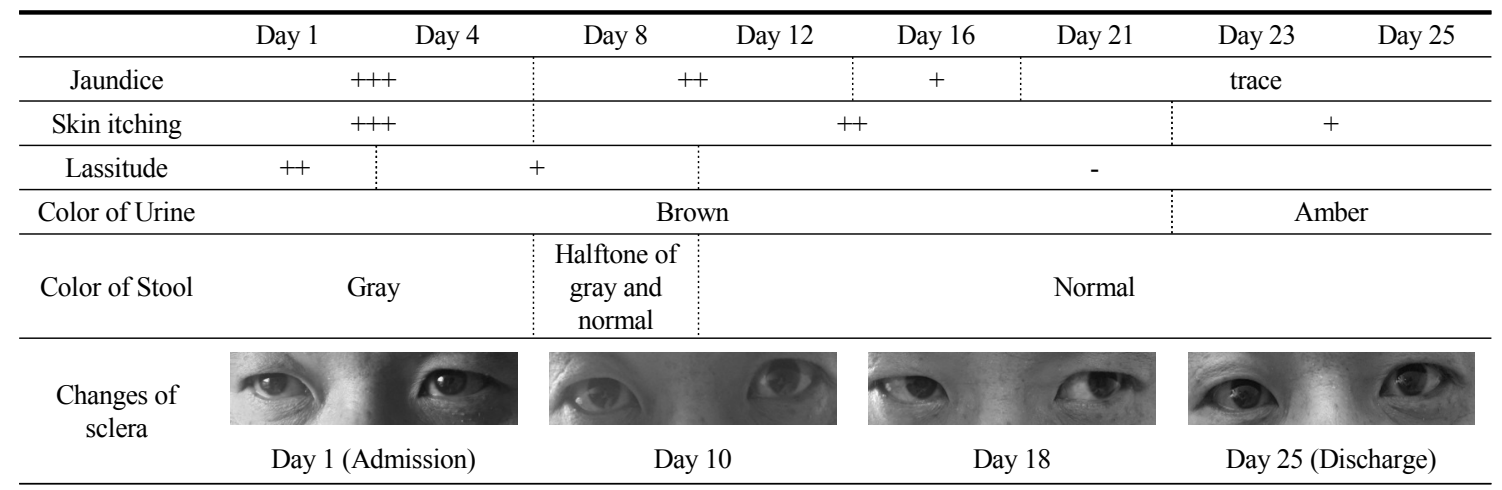

+++ severe, ++ moderate, + mild, - non-existed 
family history of the illness. He had no previous history other than one-time surgery for dermal necrosis caused by necrotizing faciitis. He had drunk 4-5 bottles of Korean liquor per week, and smoked 7 cigarettes a day. Abdominal computed tomography scan performed once June and July in Western hospital showed his condition to be normal. When admitted to the TKM clinic, he tested negative for

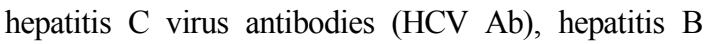
surface antigen ( $\mathrm{HBs} \mathrm{Ag}$ ), and positive for hepatits $\mathrm{B}$ surface antibodies ( $\mathrm{HBs} \mathrm{Ab}$ ), ruling out any other viral hepatitis. Anti-mitochondrial antibodies (AMA), anti-liver kidney microsomal antibodies (Anti LKM $\mathrm{Ab}$ ), auto-nuclear antibodies (ANA) were negative, and immunoglobulin $\mathrm{g}(\mathrm{IgG})$ was within the normal range. Anti-smooth muscle antibodies (ASMA) was tested as positive, but it wasn't suspected as being autoimmune hepatitis. During hospitalization, the patient also tested negative for parasite specific $\mathrm{IgG}$, if not negative the patient was infected with clonorchis sinensis. HAV IgG and HAV IgM were all positive. There were no other findings in addition to hepatomegaly and splenomegaly in the abdominal sonogram midway through the period of admission

A

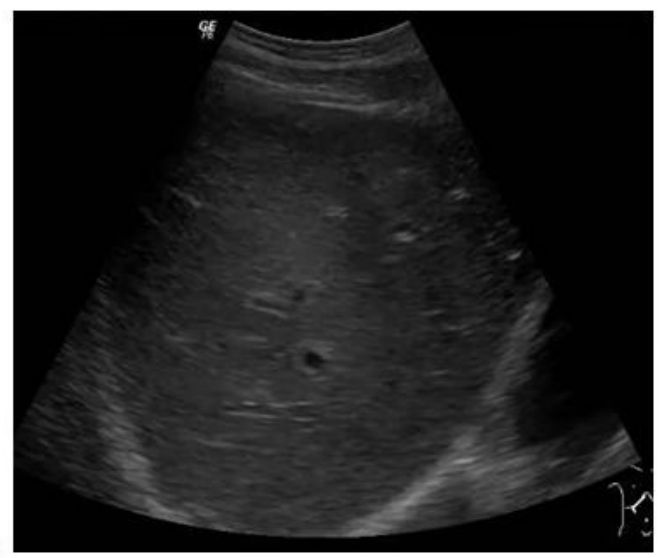

Fig. 1. Ultrasound tomographic image of the patient

A) The transvers image of liver. Hepatomegaly was seen.

B) The transvers image of spleen. Splenomegaly was seen,
(Fig. 1). Other liver diseases were ruled out, and the patient was diagnosed as having acute viral hepatitis type A with cholestatic hepatitis combining hyperbilirubinemia continuing for more than twelve weeks and typical clinical findings.

\section{Treatment}

The TKM treatment administered is as follows. Chungan extract (CGX) was prescribed four times a day. CGX is a modified herbal drug that belongs to TKM (Table 2). We chose acupoints of the Foot's Absolute Yin Liver Meridian (足前陰肝經) and Foot's Minor Yang Gallbladder Meridian (足少陽膽 經) as main meridian in accordance with TKM theories. Sterile acupuncture needles (diameter: $0.20 \mathrm{~mm}$, length: $15 \mathrm{~mm}$, Dong Bang Acupuncture Co., Korea) were bilaterally inserted to PC4 (Ximen), PC6 (Neiguan), PC7 (Daling), SP4 (Gongsun), LR13 (Zhangmen), LR14 (Qimen) and GB41 (Zulinqi) and left for 20 minutes.

The patient continued to use his prescribed medication from the Western hospital before treated with TKM. The Western medication as follows; Chlorpheniramine Maleate 2mg, Nizatidine $150 \mathrm{mg}$,

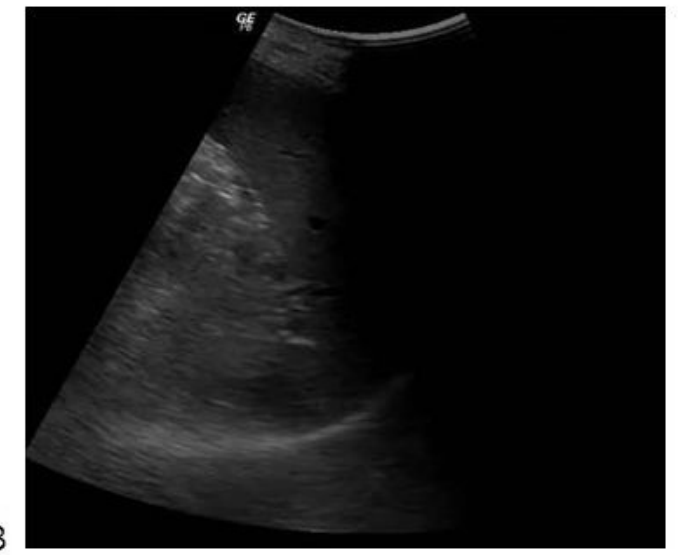


Table 2. The Composition of Chunggan extract (CGX).

\begin{tabular}{cc}
\hline Scientific name & Amount(g) \\
\hline Atremisia capillaries Thunberg & 5 \\
Trionyx sinensis Wiegmann & 5 \\
Raphanus sativus Linne & 5 \\
Atractylodes macrocephala Koidz & 3 \\
Poria cocos Wolf & 3 \\
Alisma orientalis(Sam.) Juzepczuk & 3 \\
Atractylodes chinensis Koidzumi & 3 \\
Salvia miltiorrhiza Bunge & 3 \\
Polyporus umbellatus Fries & 2 \\
Poncirus trifoliate Rafin & 2 \\
Amomum villosum Lour & 2 \\
Glycyrrhiza uralensis Fisch. & 1 \\
Aucklandia lappa Decne. & 1 \\
\hline
\end{tabular}

Biphenyl Dimethyl Dicarboxylate pill $125 \mathrm{mg}$, Ursodeoxycholic acide 50mg, Thiamine $\mathrm{HCl} 10 \mathrm{mg}$, Vitamin B with C ; however we stopped this medication as he found it to have little effect. He was given vitamin $\mathrm{B}$ and $\mathrm{C}$ mix in $5 \%$ dextrose in water (D/W) fluid for 7 days via intravenous from the first day, and this was the only treatment method belonging to Western medicine that was used.

\section{Course of symptoms, lab examination.}

The symptoms of fatigue began improving from the third day since admission, and on the fourth day, the yellow tone of his skin began to get lighter. On the eighth day the color of his stools was partly grey and partly normal color. His sclera was just as yellow as it was before; however, the color of his skin was lighter than it was on the fourth day. In addition his itching symptoms had reduced by about half of what they were at their peak. On the twelfth day since hospitalization, the color of his skin had become much lighter all over; however, his skin was still overall yellow and in appearance. In addition, the color of his stools had returned to normal color, and his fatigue was almost completely gone. On the sixteenth day since admission, his skin color was almost normal, but his sclera was still yellow. On the twenty-third day since admission, the patient's itching symptoms had reduced to about $20-30 \%$ of what they were at their peak, and his urine color returned to normal after having been dark since the day of admission. From the twenty-fourth day of admission, the total bilirubin fell under $10 \mathrm{mg} / \mathrm{dL}$ for the first time (Table 3). His sclera was as yellow as always, but his overall jaundice showed massive improvements. His whole body itching had also all but disappeared, and the color of his urine and stools had returned to normal (Table 1). He left the hospital on the twenty-fifth day due to personal reasons. Following his discharge, he consistently took CGX three times a day. 21 days after discharge all of his symptoms disappeared and he fully recovered from acute hepatitis A with cholestatic hepatitis.

\section{Discussion}

Improving sanitation levels as a by-product of socio-economic development have decreased the chances of asymptomatic infection occurring in children, and this as a result has become a cause for lowered seroprevalence of antibody for HAV in young people ${ }^{4)}$. It has been reported that seroprevalence of antibody for HAV among under 20 's in Korea have fallen from $63.8 \%$ in 1979 to $5.4 \%$ in $1996^{17}$. In an investigative report conducted in 2007, it was found that $2 \%$ of seroprevalence of anti-HAV in Korea are in their 20's, 72\%, 92\%, 94\% and $100 \%$ in their 30 's, 40 's, 50 's, and 60 's, respectively ${ }^{18)}$. Hepatitis A was very common in 2009, with over 15,000 cases reported, and the number of cases reported each year has been steadily rising in approximately over 1,000 cases $^{19)}$. Most Hepatitis A patients are reported to be between 20 and 30 years old $^{4)}$. As the incidence rate of Hepatitis $\mathrm{A}$ is growing, the number of patients who have atypical symptoms and complications is also 
Table 3. Laboratory Examination of Western and Oriental Hospital.

\begin{tabular}{|c|c|c|c|c|c|c|c|c|c|c|c|c|c|c|}
\hline \multirow{3}{*}{ Lab result } & \multicolumn{7}{|c|}{ Western Hospital } & \multicolumn{7}{|c|}{ Oriental Hospital } \\
\hline & $7^{\text {th }}$ & $30^{\text {th }}$ & $3^{\mathrm{rd}}$ & $7^{\text {th }}$ & $11^{\text {th }}$ & $17^{\text {th }}$ & $20^{\text {th }}$ & $\begin{array}{l}27^{\text {th }} \\
\text { Aug }\end{array}$ & $\begin{array}{l}31^{\text {st }} \\
\text { Aug }\end{array}$ & $\begin{array}{c}3^{\text {rd }} \\
\text { Sep }\end{array}$ & $\begin{array}{c}7^{\text {th }} \\
\text { Sep }\end{array}$ & $\begin{array}{l}10^{\text {th }} \\
\text { Sep }\end{array}$ & $\begin{array}{l}14^{\text {th }} \\
\text { Sep }\end{array}$ & $\begin{array}{l}18^{\text {th }} \\
\text { Sep }\end{array}$ \\
\hline & Jul & Jul & Aug & Aug & Aug & Aug & Aug & $\begin{array}{c}\text { Day } \\
02\end{array}$ & $\begin{array}{c}\text { Day } \\
06\end{array}$ & $\begin{array}{c}\text { Day } \\
09\end{array}$ & $\begin{array}{c}\text { Day } \\
13\end{array}$ & $\begin{array}{c}\text { Day } \\
16\end{array}$ & $\begin{array}{c}\text { Day } \\
20\end{array}$ & $\begin{array}{c}\text { Day } \\
24\end{array}$ \\
\hline $\begin{array}{l}\text { T.bilirubin } \\
(\mathrm{mg} / \mathrm{dl})\end{array}$ & 27.0 & 28.0 & 27.5 & 30.7 & 27.8 & 29.8 & 35.8 & 25.2 & 21.9 & 22.6 & 18.5 & 16.3 & 12.8 & 9.2 \\
\hline $\begin{array}{l}\text { D.bilirubin } \\
(\mathrm{mg} / \mathrm{dl})\end{array}$ & & & & No data & & & & 12.2 & 10.8 & 10.6 & 9.2 & 8.1 & 6.5 & 4.5 \\
\hline $\begin{array}{c}\text { AST } \\
\text { (IU/L) }\end{array}$ & 35 & 40 & 32 & 37 & 40 & 36 & 40 & 38 & 34 & 43 & 43 & 44 & 42 & 38 \\
\hline $\begin{array}{c}\text { ALT } \\
(\mathrm{IU} / \mathrm{L})\end{array}$ & 7 & 8 & 8 & 9 & 9 & 8 & 8 & 9 & 9 & 14 & 22 & 25 & 28 & 28 \\
\hline $\begin{array}{l}\text { r-GTP } \\
(\mathrm{IU} / \mathrm{L})\end{array}$ & 38 & 40 & 43 & 45 & 44 & 57 & 53 & 65 & 65 & 76 & 77 & 76 & 79 & 69 \\
\hline $\begin{array}{c}\text { ALP } \\
(\mathrm{IU} / \mathrm{L})\end{array}$ & 232 & 221 & 207 & 213 & 190 & 199 & 187 & 204 & 188 & 194 & 176 & 161 & 146 & 115 \\
\hline $\begin{array}{l}\text { Albumin } \\
(\mathrm{g} / \mathrm{dl})\end{array}$ & 3.7 & 3.7 & 3.6 & 3.7 & 3.7 & 3.9 & 3.7 & 3.1 & 3.1 & 3.3 & 3.2 & 3.3 & 3.5 & 3.5 \\
\hline $\begin{array}{l}\text { Creatinine } \\
(\mathrm{mg} / \mathrm{dl})\end{array}$ & 0.9 & 0.8 & 0.9 & 1.0 & 0.9 & 0.9 & 1.0 & 1.1 & 1.0 & 1.0 & 0.9 & & No data & \\
\hline PT(INR) & & & & No data & & & & 0.94 & 0.93 & 0.96 & 0.94 & 0.96 & 0.94 & 0.94 \\
\hline $\begin{array}{c}\text { Uro- } \\
\text { bilinogen }\end{array}$ & & & & No data & & & & + & + & + & trace & trace & ++ & - \\
\hline Bilirubin $^{\dagger}$ & & & & No data & & & & $+1+$ & +++ & +++ & ++ & + & ++ & + \\
\hline
\end{tabular}

increasing, which not only affects the individual patients, but also is socio-economic burden as well ${ }^{20)}$.

Mean peak of total bilirubin in acute HAV infection is generally represented as being less than $10 \mathrm{mg} / \mathrm{dL}$, and on mean, it takes about four weeks for hyperbilirubinemia to become normal bilirubin levels ${ }^{21)}$. The mean peak of total bilirubin is between $5.6-6.4 \mathrm{mg} / \mathrm{dL}$ and in-hospital treatment was administered $^{22)}$.

Some patients exhibit complications such as acute renal failure, cholestatic hepatitis, relapsing hepatitis, and prolonged course, and in severe cases, fulminant hepatic failure may occur. It is reported that fulminant hepatic failure occurs in between 0.3 $2.2 \%{ }^{7,9)}$, acute renal failure in $1.5-2.3 \%{ }^{6,9)}$, cholestatic hepatitis in $0.8-5.2 \%^{5-10)}$, and relapsing hepatitis in
$0.7-2.1 \%^{5,7)}$ of hepatitis A patients.

Acute hepatitis A with cholestatic hepatitis patients suffer from intrahepatic cholestasis, ongoing jaundice, loss of appetite, itchiness, dark-colored urine, grey-colored stools. Also total bilirubin, direct bilirubin, ALP, and r-GTP are found to be increasingly occurring in cholestatic hepatitis patients. The total bilirubin in each study regarding levels exceeding total bilirubin and ongoing illness were varied with total bilirubin above $2.5 \mathrm{mg} / \mathrm{dL}$ continuously for over eight weeks ${ }^{5}$, over $5 \mathrm{mg} / \mathrm{dL}$ for over four weeks ${ }^{9)}$, over $10 \mathrm{mg} / \mathrm{dL}$ for over ten weeks $^{8)}$, and over $15 \mathrm{mg} / \mathrm{dL}$ for over eight weeks ${ }^{23)}$.

In this case, the patient was diagnosed as having cholestatic hepatitis with typical symptoms and hyperbilirubinemia with bilirubin levels exceeding 15 
$\mathrm{mg} / \mathrm{dL}$ for over twelve weeks. The peak of total bilirubin of the patient was $35.8 \mathrm{mg} / \mathrm{dL}$. In other studies, the mean peak total bilirubin of acute hepatitis A with cholestatic hepatitis patients was $17.2 \mathrm{mg} / \mathrm{dL}$, with the mean 31 days (14 - 90 days) administered, and the time it takes for most patients' bilirubin levels to return back to normal is long at 93 days $(70-169)^{8)}$. In another study, it has been reported to be as much as 49 days of mean hospital stay ${ }^{10)}$.

The patient was diagnosed to have cholestatic hepatitis arising from typical acute hepatitis A, and no other findings, except hepatomegaly and splenomegaly, were found in the abdominal ultrasonography examination. Typical symptoms such as jaundice, itchiness, dark urine, and gray stool were present. Although the patient was treated continuously for four months, which included two months of hospitalization at Western medicine hospital, his total bilirubin levels were consistently elevated.

Western medicine currently has no specific method of treatment for hepatitis A and its complications, and opts for conservative treatment and symptomatic therapy. The treatment of hepatitis A includes continually administering conservative treatment until the illness passes naturally, or in emergency situations such as renal failure or fulminant hepatic failure, hemodialysis and liver transplantation are also administered.

Acupuncture treatment intended to improve the bile flow was performed two times daily. CGX was also prescribed four times a day. CGX is a modified herbal drug that has the meaning "cleaning the liver". It comprises herbal drugs which originated from TKM prescription. It has been proven to improve various chronic liver disease such as cholestatic liver fibrosis, liver chrrhosis, alcoholic liver disease, and chronic viral hepatitis in many patients or rat $\operatorname{model}^{24-26)}$.

In China, there are various studies underway on hepatitis $\mathrm{A}$ and its complications ${ }^{11,27)}$. However, there hasn't been much study done on hepatitis $\mathrm{A}$ in the field of TKM. Most studies done to date have been centered on chronic hepatitis B and alcoholic hepatitis, and of the five studies done in Korea by $\mathrm{Son}^{12)}, \mathrm{Min}^{13)}$, $\mathrm{Lee}^{14)}, \mathrm{Choi}^{15)}$ and $\mathrm{Kim}^{16)}$, there have been just 11 reports done on patients with acute hepatitis A. However, these studies were done on short-term hospital patients (under 2 weeks), and no studies were done on acute renal failure, cholestatic hepatitis, relapsing hepatitis, or prolonged course stemming from atypical acute hepatitis.

The patient was admitted and treated, and soon showed improvements in jaundice, itching, fatigue, and urine and stool color. At the time that the patient left the hospital, his urine and stool had returned to their normal color, and his fatigue had gone entirely. The symptom of itchiness improved to the point that it would not affect the patient's normal day-to-day living to too much of an extent. The patient's jaundice also showed massive improvements, and at his time of discharge, his skin color had returned to almost normal. The patient's sclera, however, had lost its yellow properties a fair amount, but was still partially yellow at the time of discharge. The patient's total bilirubin was considerably decreased under $10 \mathrm{mg} / \mathrm{dL}$, from $25.2 \mathrm{mg} / \mathrm{dL}$ to the pre-discharge $9.2 \mathrm{mg} / \mathrm{dL}$. The yellow color of the sclera became significantly lighter than it was at the time of admission; however being sensitive to bilirubin levels and turning yellow at just over $3 \mathrm{mg} / \mathrm{dL}$, the yellowness had not fully disappeared at the time of discharge. After discharge, the color of his sclera gradually changed from yellow to white. 21 days after, the color finally returned to normal and he had no more symptoms of cholestatic hepatitis with acute hepatitis A such as jaundice, skin itching, fatigue etc.

This study has some limitations. First, it was not possible to accurately ascertain the pattern of the patient's illness as we could not obtain blood test data from when the hepatitis A first commenced, and were not able to obtain blood test data from the time of his first time Western hospital admission from $29^{\text {th }}$ 
May to $26^{\text {th }}$ June.

Second, the patient left the hospital on the twenty-fifth day due to personal reasons. We attempted outpatient treatment, but there were difficulties with taking blood tests at regular intervals, so the patient was discharged before his total bilirubin levels had fully returned to normal.

Thirdly, we did attempt to look at photographic data; however, due to each image having differing angles and levels of illumination, we were not able to gauge an accurate comparison, and we found that it would set a poor precedent to use saturation tables or other data to quantify jaundice.

Nevertheless, the significance of this study is that it has demonstrated that hepatitis A patients who have long-term clinical outcomes with complications unseen in previous study examples can be treated with TKM with a high level of efficacy and no adverse effects. Attention surrounding hepatitis A is growing as more and more people are diagnosed, and we are now expecting there to be an increased interest in the treatment of hepatitis A using TKM. It is suggested that a more systematic study based on a larger number of hepatitis A patients be done, and we hope that this study can be a stepping stone for TKM to expand its areas of treatment to include hepatitis A.

\section{References}

1. Yun SW, Lee WK, Cho SY, Moon SH, Shin $\mathrm{HD}$, Yun SY, et al. The seroprevalence rate, vaccination rate and seroconversion rate of hepatitis A in central region of Korea. Korean J Gastroenterol. 2011;57(3):166-72.

2. Hadler SC, Webster HM, Erben JJ, Swanson JE, Maynard JE. Hepatitis A in day-care centers - a community - wide assessment. N Engl J Med. 1980;302:1222-7.

3. Lednar WM, Lemon SM, Kirkpatrick JW, Redfield RR, Fields ML, Kelley PW. Frequency of illness associated with epidemic hepatitis A virus infections in adults. Am J Epidemiol. 1985;122(2):226-33.

4. Heo JY, Song JY, Noh JY, Seo YB, Ki IS, Choi WS. Low level of immunity against hepatitis A among Korean adolescents : vaccination rate and related factors. Am J Infect Control. 2013; 41(10):97-100.

5. Kwon SY, Park SH, Yeon JE, Jeong SH, Kwon OS, Lee JW, et al. Clinical characteristics and outcomes of acute hepatitis A in Korea: a nationwide multicenter study. J Korean Med Sci. 2014;29(2):248-53.

6. Jeong SH, Jeong YM, Kim JS, Lee JH, Lee SH, Kim JW, et al. Study on the atypical features and genotype analysis of hepatitis $\mathrm{A}$ in Seongnam: a prospective, multicenter study. Clin Mol Hepatol. 2009;15(3s):105.

7. Song KS, Kim JH, Kim YS, Kim MJ, Jang WS, Jang CS, et al. Investigation about atypical clinical courses in patients with acute viral hepatitis A. Clin Mol Hepatol. 2006;12(3s):80.

8. Jeong GM, Cho YG, Cho JW, Park SH, Kim $\mathrm{IH}$, Choi CS, et al. Clinical features of cholestatic hepatitis with acute viral hepatitis A in Chunbuk province of Korea: multicenter experience. Clin Mol Hepatol. 2009;15(3s):175.

9. Yoo SH, Kim IH, Jang JW, Choi CH, Moon JC, Park JK, et al. Clinical features and risk factors for severe complications among patients with acute hepatitis A virus infection in the Jeonbuk province of Korea. Korean J Gastroenterol. 2014;63(1):25-31.

10. Petrov AI, Vatev NT, Atanasova MV. Cholestatic syndrome in viral hepatitis A. Folia Med. 2012; 54(1):30-5.

11. Ma X, Wang J, He X, Zhao Y, Wang J, Zhang $P$, et al. Large dosage of Chishao in formulae for cholestatic hepatitis: a systematic review and meta-analysis. Evid Based Complement Alternat Med. 2014;2014:328152. 
12. Son CG. A clinical report of adult acute viral hepatitis type A treated with herbal prescriptions. J Korean Oriental Med. 2007;28(4):13-7.

13. Min EK, Wang TC, Kang SW, Jeong SM, Sin HK, Park CK. A case of hepatitis A treated with Gagamsaenggan-tang. J Korean Orient Int Med. 2009;30(1s):164-8.

14. Le JE, Heo SJ, Kim HJ, Cho HJ, Kim H. Clinical studies on 5 cases of acute viral hepatitis A treated by oriental medicine. Korean J Oriental Physiol \& Pathol. 2009;23(6):1480-5.

15. Choi EJ, Song HS, Yoon WY, Yoo JS. A tae-eumin exterior-cold-disease by the cold in the esophagus's case study of diagnosed as acute hepatitis A. J Sasang Constitutional Med. 2009; 21(3):216-22.

16. Kim DW. Disease pattern identification in oriental medicine and herb medicine treatment for acute hepatitis A with jaundice - case series of 3 patients. Korean J Oriental Physiol \& Pathol. 2010;24(4):696-701.

17. Roh HO, Sohn YM, Park MS, Choi BY, Bang $\mathrm{KN}$, Ki MR, et al. A seroepidemiologic study of hepatitis A virus in the healthy children and adolescent in Kyonggi-do province. Korean J Pediatric Infectious Diseases. 1997;4(2):232-9.

18. Song YB, Lee JH, Choi MS, Koh KC, Park SW, Yoo BC, et al. The age-specific seroprevalence of hepatitis A virus antibody in Korea. Korean J Hepatol. 2007;13(1):27-33.

19. Korea Centers for Disease Control and Prevention. Statistics of surveillance of hepatitis A. Available from: URL:http://stat.cdc.go.kr

20. Park HS, Choi BY, Kwon YD. Rapid increase in the national treatment costs for hepatitis A infections in Korea. Tohoku J Exp Med. 2012; 226(1):85-93.

21. Lee EJ, Kwon SY, Seo TH, Yun HS, Cho HS, Kim BK, et al. Clinical features of acute hepatitis A in recent two years. Korean J Gastroenterol. 2008;52(5):298-303.

22. Jang JY, Yoo BW, Cho YJ, Oh JE, Hong SH, Cho CY. Analysis of the admission characteristics of patients admitted for acute hepatitis A during the last 5 years. J Soonchunhyang Medical Science. 2009;15(1):59-66.

23. Kim DH, Park KJ, Kim SH, Cho SB, Lee WS, Park $\mathrm{CH}$, et al. Clinical characteristics of patients with acute hepatitis A in Gwangju -Chonnam province for recent 10 years. Korea $\mathrm{J}$ Intern Med. 2007;72(2):131-7.

24. Cho JH, Lee YY, Seo SH, Yoo HS, Choi WJ, Lee YW, et al. A clinical report about 57 patients with chronic liver disease. J Korean Oriental Med. 2000;21(4):112-21.

25. Kim HG, Kim JM, Han JM, Lee JS, Choi MK, Lee DS, et al. Chunggan extract, a traditional herbal formula, ameliorated alcohol-induced hepatic injury in rat model. World J Gastroenterol. 2014;20(42):15703-14.

26. Kim HG, Han JM, Lee HW, Lee JS, Son SW, Choi MK, et al. CGX, a multiple herbal drug, improves cholestatic liver fibrosis in a bile duct ligation-induced rat model. J Ethnopharmacol. 2013;145:653-62.

27. Zhao H, Hou T, Shao D. Clinical study on treatment of chronic viral cholestatic hepatitis with Chishaodanpi decoction. J Tradit Chin Med. 2014;34(6):646-51. 